\title{
A study of her-2/ neu oncogene expression in benign and malignant ovarian tumors
}

\author{
Gupta S. ${ }^{1 *}$, Mehra M. ${ }^{2}$, Khattri J. ${ }^{3}$, M. $^{4}$ \\ DOI: https://doi.org/10.17511/ijmrr.2020.i02.06 \\ 1* Sumit Gupta, Associate Professor, Department of Pathology, N.I.M.S Medical College, Jaipur, Rajasthan, India. \\ 2 Manju Mehra, Professor, Department of Pathology, N.I.M.S Medical College, Jaipur, Rajasthan, India. \\ 3 Jyotsana Khattri, Assistant Professor, Department of Pathology, N.I.M.S Medical College, Jaipur, Rajasthan, India. \\ ${ }^{4}$ Madhvi, Junior Resident, Department of Pathology, N.I.M.S Medical College, Jaipur, Rajasthan, India.
}

Background: Ovarian cancers are very common worldwide with serous epithelial tumors being the most common. Her-2/neuprotoncogene encodes a protein belonging to the EGFR tyrosine kinase receptor family. Overexpression has been shown for poor prognosis in breast cancer. The study was done to find the association of ovarian tumors with Her-2/neu expression. Aim and objectives: To assess the clinicopathological profile of various ovarian tumors with special reference to age, histological type, grade, and stage of the tumor. To assess and compare the expression of Her-2/neu oncogene in benign and malignant ovarian tumors in relation to age, histological type, grade, and stage of the tumor. Method: The prospective study was done on 37 specimens received in the Department of Pathology; NIMS medical college from the period between 2015 to 2019. Results: All the benign and borderline tumors were negative for her-2/neu $.48 .6 \%$ of malignant tumors were her-2/neu positive. Conclusion: Her-2/neu positivity was seen in $24.3 \%$ of ovarian tumors. All the benign and borderline tumors were negative for her-2/neu. $48.6 \%$ of malignant tumors were her2/neu positive.

Keywords: Her-2/neuprotoncogene, Ovarian cancer, Epithelial tumors

Corresponding Author

Sumit Gupta, Associate Professor, Department of Pathology, N.I.M.S Medical College, Jaipur, Rajasthan, India.

Email: drsumitpatho@yahoo.com
How to Cite this Article

To Browse

Gupta S, Mehra M, Khattri J, Madhvi M. A study of her-2/ neu oncogene expression in benign and malignant ovarian tumors. Int J Med Res Rev. 2020;8(2):169-175.

Available From

https://ijmrr.medresearch.in/index.php/ijmrr/article/ view/1181

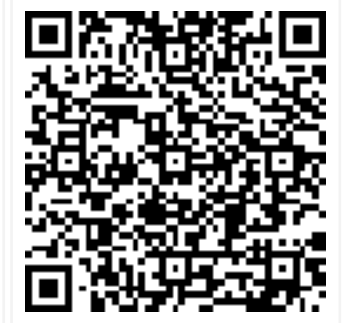

Manuscript Received 2020-03-24

Conflict of Interest No
Review Round 1 2020-04-04

Funding Nil
Review Round 2 2020-04-10

Ethical Approval Yes
Review Round 3

Accepted 2020-04-15

Plagiarism $\mathbf{X}$-checker $7 \%$

Note

(C) 2020 by Sumit Gupta, Manju Mehra, Jyotsana Khattri, Madhvi and Published by Siddharth Health Research and Social Welfare Society. This is an Open Access article licensed under a Creative Commons Attribution 4.0 International License https://creativecommons.org/licenses/by/4.0/ unported [CC BY 4.0]. 


\section{Introduction}

Ovarian cancer accounts for $6 \%$ of all female genital cancer [1]. India has the second-highest incidence of ovarian cancer globally. Ovarian cancer includes a broad spectrum of lesions ranging from localized benign tumors of borderline malignant potential through invasive adenocarcinoma. The incidence, clinical appearance, and the behavior of the different types of ovarian tumors are extremely variable. It is generally impossible to diagnose the nature of the ovarian tumor preoperatively just by clinical examination and even on exploration, though certain investigations like peritoneal fluid analysis, estimation of serum lactate dehydrogenase, fibrin degradation products, and immunological tests have been reported to be of some help in predicting the nature of the pathology.

The commonest category of ovarian tumors is epithelial tumors followed by germ cell tumors [2]. Etiology is not fully understood although the both epidemiological and genetic association has been found. Approximately $20 \%$ of ovarian malignancy is due to inherited mutations that confer elevated risk, the majority from BRCA 1 and BRCA 2 [3].

The world health organization histological classification of ovarian tumors according to the tissue of origin; surface epithelial $(65 \%)$, germ cells $(15 \%)$, sex cord-stromal (20\%), metastasis (5\%). Surface epithelial tumors are further classified by cell type (serous, mucinous, etc) and atypia (benign, borderline, or malignant. Her 2 neu (Human epidermal growth factor receptor-2) protoncogene encodes a protein belonging to the EGFR tyrosine kinase receptor family. Overexpression of her 2 neu initiates intracellular signaling pathways involved in cell proliferation, differentiation, apoptosis, and migration [4].

The ovarian epithelial carcinomas have a poor prognosis. The great prognostic significance of tumor grade is for survival. It is proposed that the histopathological factors, as well as tumor stage and histological type, should be included in the international classification of primary epithelial tumors of the ovary. There are many proposed systems of grading but the most popular is the W.H.O. grading which is directed principally at invasive epithelial ovarian carcinomas. The grading has important prognostic and therapeutic implications. The prognostic factors include the FIGO stage, histological types, tumor grade, and clinic-surgical parameters including residual disease
After debulking surgery, presence or absence of ascites, performance status, and age. FIGO stage is the most common important independent prognostic indicator.

Her-2/neu (Human epidermal growth factor receptor-2) proto-oncogene encodes a protein belonging to the EGFR tyrosine kinase receptor family. Overexpression of her-2/neu initiates intracellular signaling pathways involved differentiation, migration, and apoptosis. Amplification or overexpression has been shown to play an important role in the pathogenesis and progression of certain aggressive types of breast cancer patients.

Overexpression is also known to occur in ovarian, stomach, and aggressive forms of uterine cancer such as uterine serous endometrial carcinoma. The data regarding the expression of her 2 neu in ovarian tumors is limited in the medical literature. Hence the present study evaluated the expression of her 2 neu in ovarian lesions, its relationship to the type of malignancy and co-relation with the various clinicopathological parameters, histological grading, and staging.

\section{Method}

A prospective study was done on 37 pathology specimens of ovarian tumors received in the Department of pathology between the period of three years (2016 to 2019). The specimens were fixed in $10 \%$ formalin for histopathological examination. They were examined grossly according to the standard guidelines, with special emphasis on the size of the tumor and the presence of capsular breach. All samples were included for the study which was received during the period of study in the department.

Then the paraffin-embedded tumor section was made in the usual manner and thin sections of 5 microns cut by microtome and sections were stained by hematoxylin and eosin. The Hematoxylin and Eosin stained slides were studied under low power and high power and observations were recorded. The following parameters were specifically examined including the age of the patient, histologic type, histologic grades into grade I, II, and III. For assessing the association of Her-2/neu with tumor grade tumors were categorized into a low grade(I and II) and high grade(III).

The tumor stage was done based on FIGO staging on all primary malignant tumors of the ovary as per 
Guidelines provided by FIGO. For assessing the association of tumor stage with Her$2 /$ neuexpressions, tumors were divided into earlystage tumors (stage I and II)and tumors with latestage (III and IV). The sections with tumor and adjacent normal ovarian tissue were processed for her 2 neu immunohistochemical staining.

A case of her 2 neu positive breast carcinoma was used as the positive control. For Her-2/neu staining, after antigen retrieval, slides were stained with a polyclonal antibody against Her-2/neuoncoprotein. No ethical permission was required in this study as it was done on surgical specimens received postoperative.

All the immunostained slides were reviewed and evaluated using the following criteria- Assessment of the immunohistochemical staining for her$2 /$ neuoverexpression. The negative expression included cases with either no staining or faint to weak membranous positivity in less than $10 \%$ of tumor cells. The positive expression was considered in cases of moderate to strong membranous positivity in more than $10 \%$ of tumor cells.

\section{Results}

In study 32 ovarian tumors were studied, out of which $44.5 \%$ of tumors were benign, $5.5 \%$ were borderline and $50 \%$ were malignant.

It was found that out of 32 studied ovarian tumors, $64.9 \%$ were epithelial tumors, $21.6 \%$ were germ cell tumors, $8.1 \%$ were sex cord-stromal tumors and $5.4 \%$ were metastatic tumors.

Serous tumors were most common among all epithelial tumors $(68.8 \%)$ (Table 1$)$.

Table 1: Distribution of various ovarian neoplasm.

\begin{tabular}{|l|l|l|l|l|}
\hline \multicolumn{1}{|c|}{ Total case=37 } & Benign & Borderline & Malignant & \multicolumn{1}{c|}{ Total } \\
\hline Epithelial tumors & 9 & 2 & 13 & $24(64.9 \%)$ \\
\hline Germ cell Tumors & 4 & 0 & 4 & $8(21.6 \%)$ \\
\hline Sex-cord Tumors & 3 & 0 & 0 & $3(8.1 \%)$ \\
\hline Metastatic Tumors & 0 & 0 & 2 & $2(5.4 \%)$ \\
\hline & 16 & 2 & 19 & 37 \\
\hline
\end{tabular}

Out of a total 16 serous tumors, $45.5 \%$ were benign.

Serous adenocarcinoma was the most common malignant tumor accounting for $37.5 \%$ of all epithelial tumors and $54.5 \%$ were serous tumors (Table 2).
Table 2: Distribution of type of tumor.

\begin{tabular}{|l|l|l|}
\hline Type of tumor $(\mathbf{n}=\mathbf{3 7})$ & Her-2/neu negative & Her-2/neu positive \\
\hline Benign & 16 & 0 \\
\hline Borderline & 2 & 0 \\
\hline Malignant & 10 & 9 \\
\hline
\end{tabular}

The majority $(56.2 \%)$ of germ cell tumors were mature cystic teratoma, $18.8 \%$ were yolk sac tumors and $18 \%$ were malignant mixed germ cell tumors. Among sex cord-stromal tumors 33.3\% were fibroma, $33.3 \%$ were granulosa cell tumor, $16.7 \%$ were granulosa -theca cell tumor and $16.7 \%$ were stromal Leydig cell tumor.

The majority of epithelial tumors (505) were in the age range of $31-50$ years. Germ cell tumors were common in the age range between 31-39 years $(37.5 \%)$.

The majority of sex cord-stromal tumors (66.75) were present in the age range of 40-49 years. The majority $(63.5 \%)$ of studied ovarian tumors had a size between $5-14 \mathrm{cms}, 28.4 \%$ had a size between $15-24 \mathrm{cms}$ and only $8.1 \%$ had size less than $5 \mathrm{cms}$.

The majority of ovarian tumors were seen in multiparous women and were unilateral $(75.7 \%$ and $78.4 \%$ ) respectively. In the present study out of 13 epithelial tumors, $7.7 \%$ were grade I, $34.6 \%$ were grade II and $57.7 \%$ were grade III (Table 3 ).

Table 3: Status of Her-2 / neu and tumor grade.

\begin{tabular}{|l|l|l|}
\hline Tumor Grade $(\mathbf{n = 2 6 )}$ & Her-2/new negative & Her-2/neu positive \\
\hline I and II & $3(63.6 \%)$ & $2(36.4 \%)$ \\
\hline III & $2(19.8 \%)$ & $6(80 \%)$ \\
\hline
\end{tabular}

None of the studied benign and borderline ovarian tumors showed Her-2/neu positivity. Among the malignant tumors, $48.6 \%$ of tumors were Her- $2 /$ neu positive while $51.4 \%$ were Her-2/neu negative.

No statistical significance was found between Her$2 /$ neu expression with age or size of the tumor. Out of all epithelial tumors, $61.5 \%$ of cases were her$2 /$ neu positive and $39.5 \%$ were her- $2 /$ neunegative. In germ cell tumors $18.2 \%$ cases were Her- $2 /$ neu positive and $81.8 \%$ were Her-2/neu negative.

None of the sex cord and metastatic tumors were Her-2/neupositive. Hence the association of epithelial ovarian tumors was more with Her-2/neu than with other ovarian tumors and the difference was statistically significant. The expression of Her$2 /$ neu was not associated with the stage of ovarian tumors (Figure 1). 
The positive expression of Her-2/neu was more in patients with high-grade ovarian tumors in comparison to low grade. Out of all studied malignant ovarian tumors, maximum Her-2/neu positivity (72.2\%) was present in serous adenocarcinoma and its association with Her-2/neu was statistically significant as compared to others.

The current study suggested that her-2/neu deserves further evaluation as a prognostic marker in epithelial tumors (Figure 2) (Figure 3-7).

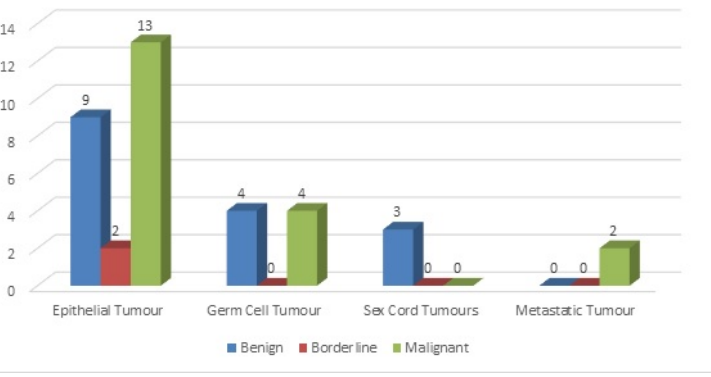

Fig-1: Distribution of various ovarian neoplasm.

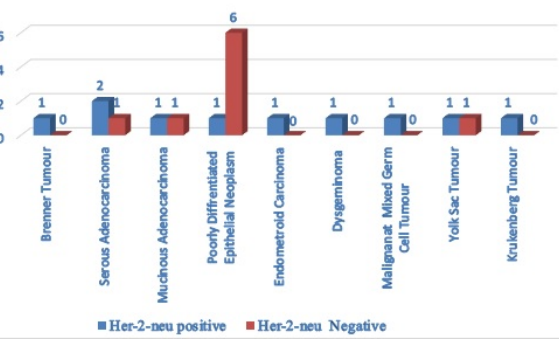

Fig-2: Status of HER-2/NEU and histological type of cancer.

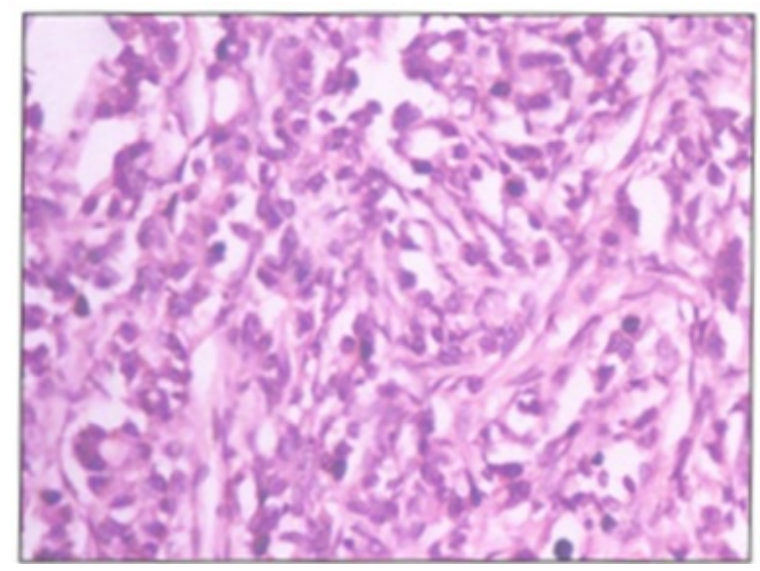

Fig-3: Microphotograph of metastatic adenocarcinoma (Krukenberg tumor) ( $H$ and $E$ $400 \mathrm{x})$.

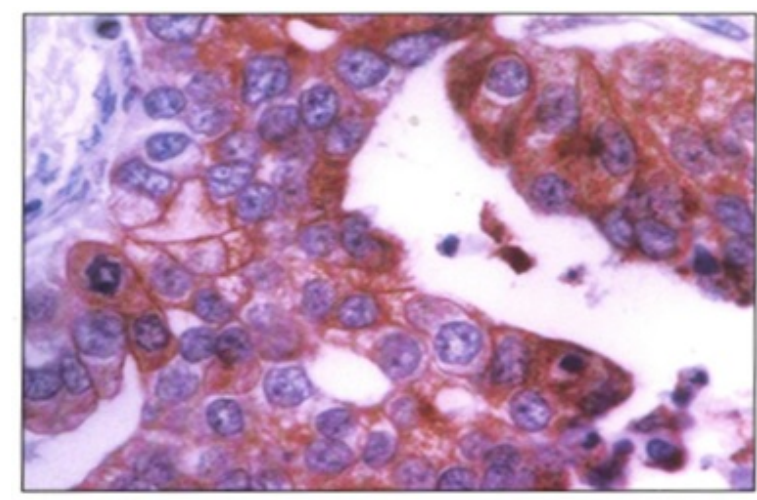

Fig-4: Microphotograph of grade III serous adenocarcinoma showing membranous positivity in tumor cells (Her-2/neu immunostain).

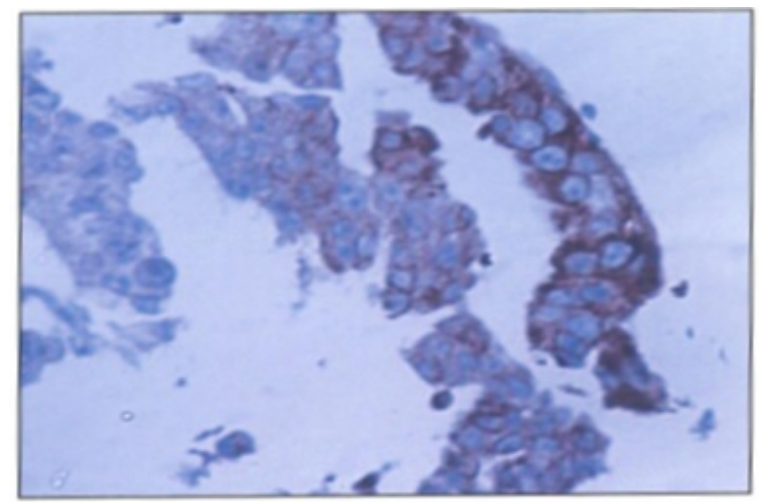

Fig-4: Microphotograph of Grade III serous adenocarcinoma showing membranous positivity in tumor cells (Her-2/neu immunostain).

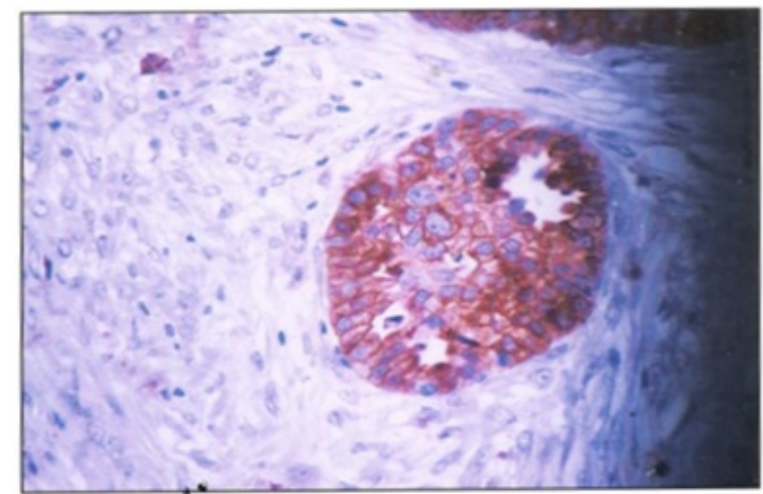

Fig-5: Microphotograph of grade II serous adenocarcinoma showing membranous positivity of tumor cells (Her-2/neu immunostain). 


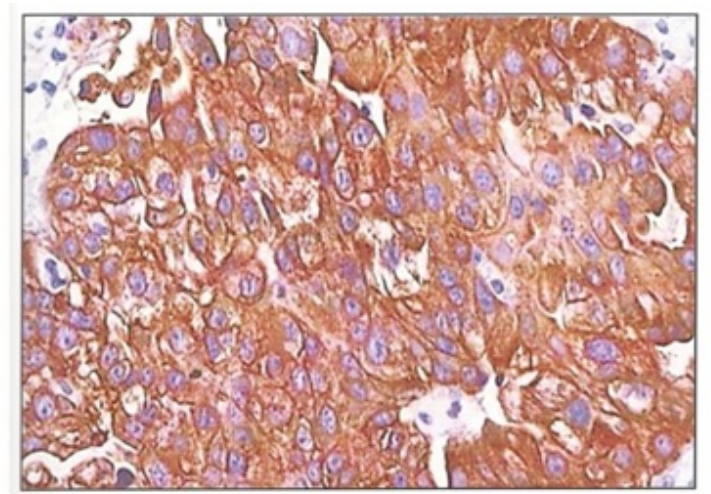

Fig-6: Microphotograph of poorly differentiated epithelial neoplasm showing membranous positivity of tumor cells (Her$2 /$ neu immunostain).

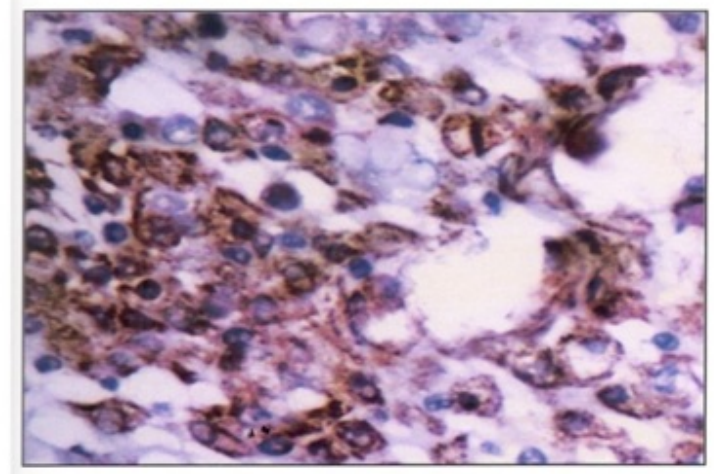

Fig-7: Microphotograph of yolk sac tumor showing membranous positivity of tumor cells (Her-2/neu immunostain).

\section{Discussion}

Ovarian cancer is the fifth leading cause of cancer death among women and has the highest mortality rate of all gynecologic cancers [5]. Ovarian cancer is diagnosed in later stages because the inaccessible anatomic location of the ovaries and asymptomatic nature of the disease hinders the detection of cancer while it is still confined to the ovary.

The prognostic factors include the FIGO stage, histological type, tumor grade, and clinic-surgical parameters include residual disease after debulking surgery, presence or absence of ascites, performance status, and age. FIGO stage is the most important independent prognostic factor.

The current study evaluated the clinicopathological profile of various ovarian tumors and expression of Her-2/neu in ovarian lesions, its relationship to its type of malignancy, and correlation with clinico-
Pathological factors like age of the patient, size of the tumor, histological grading, and staging.

In the current study, 16 cases were benign, 2 cases were borderline and 19 cases were malignant with surface epithelial tumors were most common $(68.8 \%)$.

The majority of benign tumors were in age between 30-39 years and the majority of malignant epithelial tumors were in the range between 40-49 years in comparison with other studies [6]. In the current study, benign cystic teratoma was commonest among all germ cell tumors accounting for $56.2 \%$ of all germ cell tumors and $12.1 \%$ of all ovarian tumors, and most of them presented in the age range of 30-39years.

However malignant germ cell tumors were present at the age of fewer than 30 years. Sex cord tumors, granulosa cell tumors, and fibromas were most common each constituting around $2.7 \%$ of all ovarian tumors.66.7\% of sex cord tumors were in age between 40-49 years. Metastatic tumors constituted $5.4 \%$ of all ovarian tumors and were seen in the age above 30 years.

$63.5 \%$ tumors had a size of $5-14 \mathrm{cms}, 28.4 \%$ had size more than $15 \mathrm{~cm}$ only and $8.1 \%$ had size less than $5 \mathrm{cms}$.

$24.3 \%$ of ovarian tumors were seen in nulliparous women and $75.7 \%$ of ovarian tumors were seen in multiparous women. Among epithelial tumors, $89.6 \%$ were seen in multiparous women. The majority of germ cell tumors were seen in nulliparous women probably due to the young age of onset.

$78.4 \%$ of ovarian tumors were unilateral and all the metastatic tumors were bilateral. $21.2 \%$ of malignant tumors were stage $\mathrm{I} ; 27.3 \%$ were stage II and $51.5 \%$ were stage III. Out of a total of 13 epithelial tumors, whose grading was done; $7.7 \%$ were grade I, $34.6 \%$ were grade II, $57.7 \%$ were grade III.

The proportion of ovarian cancers overexpressing her -2 /neu is a matter of debate. Various studies have reported that between $5 \%$ and $30 \%$ of ovarian tumors overexpress her 2 neu [7]. In the current study, $24.3 \%$ of all ovarian tumors showed her $-2 /$ neu positivity of which all were malignant $(48.6 \%)$ comparable to another study $[8,9]$.

No statistically significant association of her 2 neu positivity with age and size of the tumor was found 
In concordance with another study $[10,11]$.

Among all malignant epithelial tumors, $61.5 \%$ of cases were her- $2 /$ neu positive and $39.5 \%$ were negative. In germ cells, tumor $18.2 \%$ cases were her 2 neu positive and rest $81.8 \%$ were negative.So, her-2/neu was statistically significantly associated with epithelial tumors than with other ovarian tumors compared to another study [12] and with non-cordance with another study $[13,14]$. The non-epithelial tumors of ovary rarely showed her2/neu expression comparable to another study [8]. HER2 expression is associated with a worse outcome of ovarian cancer, implicating HER2 may be a potential prognostic indicator for ovarian cancer patients [16].

In the present study out of $8(48.5 \%)$ patients with early-stage ovarian cancer (Stage I and 2); $43.7 \%$ patients were her-2/neu positive and $56.3 \%$ were her-2/neu negative while out of $51.5 \%$ patients were with advanced-stage ovarian cancer (stage III/IV), with $64.7 \%$ cases were her- $2 /$ neu positive and $35.3 \%$ were her -2 /neu negative; concluding the expression of her- $2 /$ neu is independent of ovarian cancer stage $[14,15]$. The number of cases the current study received during the period of study was limited. Hence the association of various ovarian tumor type and Her$2 /$ neu co-relation need to be a further study in a large sample size.

\section{Conclusion}

Epithelial tumors were commonest among all ovarian tumors studied; most common being serous tumors. The majority of tumors were unilateral and were seen in multiparous women and the majority had a size between 5-14 cms. The majority of tumors were in high grade and presented in advanced stages. Her-2/neu positivity was seen in $24.3 \%$ of ovarian tumors. All the benign and borderline tumors were negative for her- $2 /$ neu. $48.6 \%$ of malignant tumors were her- $2 /$ neu positive. Epithelial tumors were significantly associated with her-2/neu with serous adenocarcinoma showing maximum association as compared to other tumors.

\section{What does the study add to the existing knowledge}

Her-2/neu expression is significantly associated with tumors of high grade but had no correlation with the
Stage of the tumor. No association is found with the age of the patient and the size of the tumor. Though the stage and grade of the tumor are the most important prognostic indicator.

\section{Author's contribution}

Dr. Sumit Gupta: Concept, study design, manuscript preparation

Dr. Manju Mehra: Manuscript preparation

Dr. Jyotsana Khattri: Statistical analysis

Dr. Madhvi: Study design

\section{Reference}

01. Deodhar KK, Suryawanshi P, Shah M, Rekhi B, Chinoy RF. Immature teratoma of the ovary- a clinicopathological study of 28 cases. Indian J Pathol Microbiol. 2011;54(4)730-735. Available from: [Article] [Crossref]

02. Swamy GG, Satyanarayana N. Clinicopathological analysis of ovarian tumors-A study on five years samples. Nepal Med Coll J. 2010;12(4)221-223.

[Crossref]

03. Whiiermore AS, Harris $\mathrm{R}$, Itnyre $\mathrm{J}$. Characteristics relating to ovarian cancer risk studies collaborative analysis of 12 us casecontrol studies- II, invasive epithelial ovarian cancers in white women collaborative ovarian cancer group. Am J Epidemiol. 1992;136(10)1184-1203. doi: [Article] [Crossref]

04. Yarden $Y$, Slinkwoshi M. Untangling the Erb B signalling network. Nat Rev Mol Cell Biol. 2001;2(2)127-137. doi: [Article] [Crossref]

05. Smith RA, Cokkinides $V$, von Eschenbach $A C$, Levin B, Cohen C, Runowicz CD, et al. American Cancer Society guidelines for the early detection of cancer. CA Cancer J Clinic. 2002;52(1)8-22. doi: [Article] [Crossref]

06. Tyagi SP, Madn A. Epithelial tumors of the ovary. Indian J Pathol Microbiol. 1978;21;281-289.

[Crossref]

07. Hellstrom I, Goodman G, Pullman J, Yang Y, Hellstorm KE. Overexpression of Her 2 neu in ovarian cacinomas. Cancer Res. 2001;61(6)2420-2423.

[Crossref] 
08. Kacinski BM, Mayer AG, King BL, Carter D. NEU protein overexpression in benign, borderline and malignant ovarian neoplasms. Gyneco Oncol. $1992 ; 44(3) 245-253$.

doi: [Article] [Crossref]

09. Marwah N, Bansal C, Gupta S, Singh S, Arora B. Immunohisto chemical study of the expression of HER-2/neu oncogene in ovarian lesions. Indian J Pathol Microbiol. 2007;50(3)489-492.

[Crossref]

10. Nielsen SN, Scheithauer BW, Gaffey TA. Gliomatosis peritonei. Cancer. 1985;56(10)2499-2503.

[Article] [Crossref]

11. Sueblinvong $T$, Manchana $T$, Khemapech $N$, Triratanachat S, Termrungruanglert W, Tresukosol D. Lack of prognostic significance of HER-2/neu in early epithelial ovarian cancer. Asian Pac J Cancer Prev. 2007;8(4)502-506.

[Crossref]

12. Marinaş MC, Mogoş G, Ciurea R, Mogoş DG. EGFR, HER2/neu and Ki67 immunoexpression in serous ovarian tumors. Rom J Morphol Embryol. 2012;53(3)563-567.

[Crossref]
13. Rubin SC, Finstad CL, Wong GY, Almadrones L, Llyod KO. Pognostic significance of HER -2/neu expression in advanced epithelial ovarian cancer- a multivariate analysis. Am J Obstet Gynecol. 1993;168;162-169.

[Crossref]

14. Singleton TP, Perrone T, Oakley G, Carson L, Niehans GA, Cha SS, et al. Activation of c-erbB2 and prognosis in ovarian carcinomas. Cancer. 1994;73(5)1460-1466. doi: [Article] [Crossref]

15. Høgdall EV, Christensen L, Kjaer SK, Blaakaer J, Bock JE, Glud E, et al. Distribution of HER-2 overexpression in ovarian carcinoma tissue and its prognostic value in patients with ovarian carcinoma- From the Danish "MALOVA" Ovarian Cancer Study. Cancer. 2003;98(1)66-73.

[Article] [Crossref]

16. Luo $H$, Xu X, Ye $M$, Sheng $B$, Zhu X. The prognostic value of HER2 in ovarian cancer- a meta-analysis of observational studies. PloS one. 2018;13(1).

doi: [Article] [Crossref] 